the person's criminal responsibility, the relation between the individual's psychiatric problem and the crime, the person's competency to stand trial, the possibility of deterioration of the individual's condition as a result of enforcement of the judgement, and the availability of psychiatric treatment and regular follow-up.

This section consists of six articles.

\section{Section 5. Special groups}

This section relates to children and adolescents, elderly people and those who are not capable of making decisions regarding their affairs. It has four articles.

\section{Section 6. Other rules}

In this section, the responsibilities of both the judiciary and the executive (including the Ministry of Health, the Welfare Organisation and insurance companies) to psychiatric patients are addressed. This section comprises 20 articles.

\section{Discussion}

The new draft Mental Health Act in Iran has been prepared in collaboration with the departments of psychiatry and clinical psychology of most medical schools in the country and the Iranian Psychiatric Association. Due to the practical nature of the law, one expects many of the current problems facing patients, carers and members of staff to be resolved after the Act is ratified.
The Bill is presently at the Ministry of Health, but is due to be submitted to Parliament. The next stage will be to educate and prepare guidelines for patients and carers. We hope we achieve our objectives in the near future.

\section{References}

Asgharzadeh-Amin, S. \& Shahmohammadi, D. (2004) Existing laws regarding patients in Iran. Andisheh and Raftar, 4, 71-96. (Journal and article in Farsi.)

Hojjati-Ashrafi, G. (1990) Comprehensive Laws and Regulations of Criminal Activities in Iran. Ganje Danesh. (In Farsi.)

Jafarzadeh, A. (1996) Islamic Penal Code in Iran. Bazargani. (In Farsi.)

Mane, P. \& Gandevia, K. Y. (1993) Mental Health in India: Issues and Concerns. TATA Institute of Social Sciences.

Segal, S. P. (1989) Civil commitment standards and patient mix in England/Wales, Italy, and the United States. American Journal of Psychiatry, 146, 187-193.

Tofighi, H. (1996) Law and psychiatry. Journal of Forensic Psychiatry, 7, 33-69. (Journal and article in Farsi.)

Wall, S., Hotopf, M., Wessley, S., et al (1999) Trends in the use of the Mental Health Act: England 1984-96. BMJ, 318, 1520-1521.

World Health Organization (2003a) Draft WHO Manual on Mental Health Legislation. WHO

World Health Organization (2003b) WHO Checklist on Mental Health Legislation, Mental Health Policy and Services. WHO.

World Health Organization (2006a) WHO-AIMS Report on the Mental Health System in Iraq. WHO.

World Health Organization (2006b) WHO-AIMS Report on the Mental Health System in Egypt. WHO and Ministry of Health, Cairo.

World Health Organization (2008) WHO-AIMS Report on the Mental Health System in Tunisia. WHO and Ministry of Health, Tunis.
MENTAL HEALTHLAW PROFILE

\title{
Mental health law profile: the United Arab Emirates
}

\author{
Ghanem Alhassani ${ }^{1}$ and Ossama T. Osman²
}

1Adjunct Lecturer and Consultant Psychiatrist, Alain Hospital, Abu Dhabi, United Arab Emirates, emailossamao@uaeu.ac.ae ${ }^{2}$ Associate Professor and Consultant Psychiatrist, Alain Hospital, Abu Dhabi, United Arab Emirates

\begin{abstract}
There are two federal laws in the UAE from 1981 that are specific to people with mental illnesses and disabilities. Efforts are presently being made to develop other laws addressing the protection of the vulnerable population, including women, children and the elderly. A new updated Mental Health Act is needed to keep in line with the UAE's major leaps achieved in healthcare.
\end{abstract}

The United Arab Emirates (UAE) was established on 2 December 1971 as a federation of seven emirate states (Abu Dhabi, Dubai, Sharjah, Ajman, Umm al-Qaiwain, Fujairah and Ras al-Khaimah). The constitution of the UAE defines the division of powers between the federal and the local authorities. The highest authority in the country is the Supreme Council of the Federation, which consists of the rulers of all seven emirates. The Council elected the first President of the Federation (the late Sheikh Zayed Al Nahyan). In 1981 the President signed one federal law relating to mental illness (Federal Law 28) and another relating to mental disability (Federal Law 29). These laws (together with related professional codes of conduct) remain the principal legislation specific to mental health. Regulations were later developed with relevance to mental health as part of the general Medical Code of Ethics for health services. In 2008 an updated federal law on medical responsibility dealt with medical malpractice. 


\section{Federal mental health laws}

\section{Federal Law 28 (1981) concerning the detention and treatment of people with a mental disorder}

This Law consists of 15 articles. It covers all aspects of involuntary detention in medical facilities. The ground for compulsion emphasises the presence of psychosis alone or in combination with any other mental disorder, intellectual disability or personality disorder, as long as it is 'accompanied by loss of contact with reality'. The legal age of consent to treatment was determined to be 18 years. The decision to detain a patient is made by a clinical evaluation board composed of the head of the psychiatry department and at least two specialist psychiatrists or neurologists (although it is no longer considered appropriate for neurologists to make decisions regarding the detention of psychiatric patients). Each psychiatric facility is expected to have its own board.

Article 3 describes mental capacity in lay language. It states that voluntary admission of adult patients with psychosis should follow their request, if they are in a state which allows them to express their will; if the age of consent has not been attained, voluntary admission shall be upon the request of the legal custodian.

Article 4 determines the grounds for compulsory detention. If it seems that a person has a psychosis and is likely to violate security or public order or cause serious bodily harm to self or another, detention shall be upon an order from the police or the judicial authority (a court). The patient's relatives may ask the authority to adopt detention procedures. Those eligible are specified as relatives of first degree or next of kin. In the event of their absence, the head of the tribe or his deputy or the police may initiate the procedure.

Article 5 indicates that in the event of compulsory detention the board must decide within 48 hours whether the patient's state genuinely requires his or her detention. The initial duration of detention must not exceed 1 week. If the board at its discretion after this period deems that the patient is not in a state that allows him or her to leave, it may extend this period, for 1 month at most, although the extension may be repeated. The authority has to be notified of every extension, and the patient's relatives or other party applying for the person's detention may oppose this extension. The board must give its decision within 72 hours and this decision is irrevocable.

Article 6 requires the psychiatric facility to notify the judicial authority of a patient's compulsory detention within 48 hours, in order to begin the process of dealing with the patient's assets.

Article 12 indicates that if his or her mental condition requires the patient to have special custody, the facility may resort to the assistance of the police to provide it.

Similar to other countries in the region, the family is typically the primary support network for patients (Ikkos, 2013) and is involved in decision-making about the continuation or discontinuation of involuntary procedures.

\section{Federal Law 29 (1981) concerning the rights of people with mental disability}

This elaborate law consists of nine articles that define disability and outline the guarantees for the rights of individuals with temporary and permanent disabilities. Its definition includes any person with reduced mental, interactive, educational or psychological capacity. It defines discrimination and guarantees the rights of people with disabilities to receive all the services they need. It requires awareness programmes to be run. It prohibits aggression against people with mental disabilities and arbitrary deprivation of their liberty and ensures legal assistance and protection of their medical records and related documents.

Article 7 ensures that people with mental disabilities have the right to freedom of speech and opinion through various means of communication, and to request, receive and transfer information on an equal footing with others. Article 8 ensures the protection of their medical records and personal affairs.

Article 9 requires the establishment of educational and training centres for care, training and rehabilitation in preparation for integration in society. It also provides programmes and training for families on the optimum methods to deal with relatives with a mental disability.

\section{Laws under development with relevance to mental health}

There are three important laws relating to mental health currently under development. The first is a federal law concerning mental health (in draft) which consists of 94 articles in 10 chapters. It covers definitions of mental illness, scope, objectives, rights of patients, confidentiality, types of admission, grounds for detention and treatment in a mental hospital. It identifies the balance between protecting the public and protecting the human rights of the patient. Relationships with the authorities (e.g. the police) and oversight responsibilities are covered in Chapter 6. In Chapter 7 the new law describes involuntary non-in-patient therapy (compulsory home-based or communitybased treatment). Chapter 8 includes guidelines on the management of patients (including minors) with a mental illness. The family will continue to play a prominent role in treatment decisions but social workers will take on responsibilities in support of the family, which should ease the burden on relatives. The proposed law is consistent with recommendations from the World Health Organization's Eastern Mediterranean Region (Abou-Saleh, 2012).

The second proposed federal law is to protect elderly people and is designed to mainstream elderly care across the seven emirates and to address medical insurance, negligence and abuse.

The third is a child protection law, known as the 'Wadima Law', so named after an 8-year-old 
Box 1. Provisions for mental health outside the specific legislation

- Constitutional guarantees of the promotion of human rights

- Federal Act 43 of 1992 for the right to healthcare for all citizens

- Constitutional article 19, concerning the rights of incarcerated persons to healthcare (1971)

- Federal Anti-Human Trafficking Act 51 of 2006 to combat human trafficking offences and various forms of exploitation of human beings, particularly women and children

- International Convention on the Elimination of All Forms of Racial Discrimination (1974)

- The Convention on the Rights of the Child (1997)

- The Convention on the Elimination of All Forms of Discrimination Against Women (2004)

- The Geneva Convention on international humanitarian law (1972)

- Cooperation agreement with UNICEF in 2005 to provide for the social and psychological rehabilitation, repatriation and local integration of child camel jockeys

Source: Working Group on the Universal Periodic Review (2008).

\section{Other laws with provisions for mental health}

The numerous constitutional guarantees of the promotion of human rights and guarantees in international treaties and programmes as they relate to the UAE are detailed in Box 1.

\section{Discussion}

The UAE's present mental health law regulates compulsory admissions to mental health facilities. However, there is currently no unified procedure for its consistent implementation. The language of the law needs to be updated to incorporate modern, internationally used terminology (e.g. the term 'legal guardian' instead of 'legal custodian', 'interpersonal' instead of 'interactive'). A new comprehensive draft Federal Mental Health Act is in its final review and approval stages. The hope is to produce consistent and sustainable changes in mental health practices throughout the UAE.

\section{References}

Abou-Saleh, M. T. (2012) The World Federation for Mental Health: building its constituency in the East Mediterranean Region for improving care and the lives of the mentally ill and their families. Arab Journal of Psychiatry, 23, 178-184.

Ikkos G. (2013) Mental health law profiles. International Psychiatry, 10,88 .

Working Group on the Universal Periodic Review (2008) United Arab Emirates. United Nations General Assembly. Available at https://www.mofa.gov.ae/EN/Documents/ HumanRightsCouncil2008.pdf (accessed June 2015).

\title{
SPECIAL PAPER \\ Mental health and psychosocial support for children in areas of armed conflict: call for a systems approach
}

\author{
M. J. D. Jordans ${ }^{1}$ and W. A. Tol ${ }^{2}$
}

'Senior Lecturer, Centre for Global Mental Health, Institute of Psychiatry, Psychology \& Neuroscience, King's College London, London, UK, email mark. jordans@kcl.ac.uk

${ }^{2}$ Dr Ali \& Rose Kawi Assistant Professor, Department of Mental Health, Johns Hopkins Bloomberg School of Public Health,

Baltimore, USA
This paper focuses on the question of whether separate attention to children who have faced specific conflict-related events is justified, or whether the scarce resources for mental health should be spent on the development of services for children more broadly in low- and middleincome countries (where most contemporary armed conflicts are taking place). It is argued that a systems approach to mental health and psychosocial support for children is warranted.

Mental health problems affect 10-20\% of children and adolescents worldwide (Kieling et al, 2011). Especially in low- and middle-income countries (LMICs), there is a substantial gap in the available resources to meet the mental health needs of children (Belfer, 2008). Among these LMICs, there are currently 23 countries where armed conflict results in grave acts committed against children (United Nations, 2014). Armed conflicts have a negative impact on the mental health and psychosocial well-being of individuals, including psychological distress and mental disorders, as well as negative impacts on the families and communities in which children grow up (Barenbaum et al, 2004).

In response, psychosocial and mental health interventions for children affected by armed conflict have been developed. Types of interventions vary widely, with respect to both aim (from promotion, prevention and treatment approaches) and modality (spanning creative and recreational group activities; dance and movement therapy; parental support; individual psychotherapy) (Jordans et al, 2009b). School-based interventions are most often represented in the literature 